LXXVII.

\title{
A CASE OF THROMBUS AND REMOVAL OF INTERNAL JUGULAR VEIN.
}

\author{
By Frank Allport, M. D.,
}

\section{Chicago.}

Mrs. V. K., age about 35 years, was first seen by Dr. Tibbits of Menominee, Michigan, May 13th, 1912. She reported that she had "caught cold" and had a severe pain in her right ear. In about three days this was followed by a discharge. For about three weeks the pain was evident at irregular intervals and the discharge continued constantly. She then consulted Dr. Tibbits, who ascertained that she had a temperature of $103.8^{\circ}$ and a pulse of 100 .

She was sent to the hospital and Dr. W. O. McBride of Marinette, Wisconsin, was called in consultation. He discovered a small perforation in the anterior inferior quadrant of the drum head, which he materially enlarged. There was slight sagging of the posterior superior wall of the meatus and some tenderness over the mastoid tip, but no swelling of the mastoid tissues. That evening the temperature advanced to $105^{\circ}$ and the pulse to 120 . Before morning the temperature fell to $103^{\circ}$, but in a few hours advanced again to $105^{\circ}$.

On May 14th Dr. McBride performed a simple mastoid operation and found pus in the cells and a healthy appearance of the bone covering the sigmoid sinus. The temperature rapidly dropped to $101^{\circ}$ and the pulse to 100 . From this on the temperature and pulse made rapid upward and downward flights, and on May 17th, 19th and 20th she had chills. Her mental condition remained clear.

On May 20th I removed a large thrombus from the sinus and secured a free flow of blood from both the torcular and bulbar directions. Her temperature immediately dropped to $99.8^{\circ}$ and her pulse to 100 . Both temperature and pulse gradually became lowered to almost normal until May 27th, when she had another chill and her temperature shot up to $105^{\circ}$ and 
her pulse to 150 . By the next day the temperature was $100^{\circ}$ and the pulse 100. May 29th she had another chill, followed by another, and her temperature reached $107^{\circ}$ and her pulse 160. That night when I saw her she was in no material pain and was clear mentally. Her temperature was $100^{\circ}$ and her pulse 110. Tine differential blood count, made by Dr. E. V. McComb of Menominee, showed the polynuclear cells to have a percentage of 99 per cent. There was no neck tenderness. I removed the internal jugular vein from the mastoid process to the clavicle. It was so utterly collapsed, owing to the reformation of the thrombus above, that its anatomic identity was extremely difficult to establish. It was not much larger than the pneumogastric nerve. After its removal I again removed the sigmoid thrombus and established hemorrhage from the torcular direction. The wound was then closed and drainage maintained. The next day the temperature was $104^{\circ}$ and the pulse 150 , but from then on they steadily decreased, and July 6th she left the hospital entirely well, with a hearing of seven inches by Dr. McBride's watch.

I report this case, as I believe that all similar cases should be reported, as an encouragement to decisive action in bad cases. 